Check for updates

Cite this: RSC Adv., 2019, 9, 2217

\title{
Synthetic ionophores as non-resistant antibiotic adjuvants $\uparrow$
}

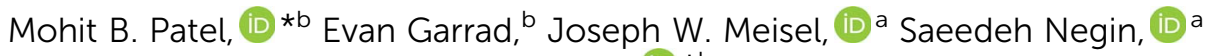 \\ Michael R. Gokel ${ }^{a}$ and George W. Gokel (D)*b
}

Antimicrobial resistance is a world-wide health care crisis. New antimicrobials must both exhibit potency and thwart the ability of bacteria to develop resistance to them. We report the use of synthetic ionophores as a new approach to developing non-resistant antimicrobials and adjuvants. Most studies involving amphiphilic antimicrobials have focused on either developing synthetic amphiphiles that show ion transport, or developing non-cytotoxic analogs of such peptidic amphiphiles as colistin. We have rationally designed, prepared, and evaluated crown ether-based synthetic ionophores ('hydraphiles') that show selective ion transport through bilayer membranes and are toxic to bacteria. We report here that hydraphiles exhibit a broad range of antimicrobial properties and that they function as adjuvants in concert with FDA-approved antibiotics against multi-drug resistant (MDR) bacteria. Studies described herein demonstrate that benzyl $\mathrm{C}_{14}$ hydraphile $\left(\mathrm{BC}_{14} \mathrm{H}\right)$ shows high efficacy as an antimicrobial. $\mathrm{BC}_{14} \mathrm{H}$, at sub-MIC concentrations, forms aggregates of $\sim 200 \mathrm{~nm}$ that interact with the surface of bacteria. Surface-active $\mathrm{BC}_{14} \mathrm{H}$ then localizes in the bacterial membranes, which increases their permeability. As a result, antibiotic influx into the bacterial cytosol increases in the presence of $\mathrm{BC}_{n} \mathrm{Hs}$. Efflux pump inhibition and accumulation of substrate was also observed, likely due to disruption of the cation gradient. As a result, $\mathrm{BC}_{14} \mathrm{H}$ recovers the activity of norfloxacin by 128 -fold against resistant Staphylococcus aureus. $\mathrm{BC}_{14} \mathrm{H}$ shows extremely low resistance development and is less cytotoxic than colistin. Overall, synthetic ionophores represent a new scaffold for developing efficient and non-resistant antimicrobial-adjuvants.

Received 13th September 2018 Accepted 31st December 2018

DOI: $10.1039 / c 8 r a 07641 c$

rsc.li/rsc-advances transfer from the bacteria producing them could eventually lead to resistance. Such discovery methods are critical to address the antibiotic-resistance crisis, but differ fundamentally from the approach presented here.

We have designed and synthesized amphiphiles called hydraphiles that form cation-selective channels in membranes. Some of these compounds exhibit significant antimicrobial properties attributed to the disruption of ion gradients in bacteria. ${ }^{4}$ Numerous synthetic amphiphiles have been reported, but studies of them were generally limited either to ion transport $^{5}$ or to a simple survey of antimicrobial potency. ${ }^{6}$ We report here that hydraphiles form cation selective channels in membranes and recover antimicrobial potency against multidrug resistant (MDR) bacteria by increasing the cytosolic concentration of antibiotics within the pathogen.

Poor membrane permeability and efflux pump function have long been recognized as important contributors to bacterial resistance. ${ }^{7}$ Efflux pump proteins require a cation gradient or ATP hydrolysis to drive xenobiotics from the bacterial cytosol. ${ }^{8,9}$ Disruption of these gradients offers a potential mechanism by which resistance may be diminished or eliminated. Antimicrobial resistance in Gram-negative bacteria is typically a combination of second membrane-diminished influx and
${ }^{a}$ Department of Chemistry, Biochemistry University of Missouri - St. Louis, 1 University Blvd., St. Louis, MO 63121, USA. E-mail: gokelg@umsl.edu; Fax: +1-314/516-5342; Tel: $+1-314 / 516-5321$

${ }^{b}$ Department of Biology, University of Missouri - St. Louis, 1 University Blvd., St. Louis, MO 63121, USA

$\dagger$ Electronic supplementary information (ESI) available. See DOI: $10.1039 / \mathrm{c} 8 \mathrm{ra07641c}$ 
increased antibiotic efflux. ${ }^{\mathbf{1 0}}$ Membrane active molecules, such as colistin ${ }^{\mathbf{1 1}}$ and daptomycin, ${ }^{\mathbf{1 1}}$ disrupt bacterial membranes and permit increased antimicrobial influx. Sadly, resistance even to these potent antibiotics has recently emerged. ${ }^{12}$ However, to our knowledge, there is no report of any synthetic adjuvant that can inhibit efflux pump activity and increase membrane permeability to antibiotics. The use of synthetic ion channels as antimicrobial adjuvants not only comprises a new approach, but it also impedes resistance development, as these synthetic amphiphiles are not produced by bacteria.

We report here the application of synthetic amphiphiles (hydraphiles) that penetrate membranes and form cation selective channels. Hydraphiles form aggregates of $\sim 200 \mathrm{~nm}$ that attach to the surface of bacteria. The surface-attached hydraphiles then localize in the Escherichia coli membranes, transport potassium $\left(\mathrm{K}^{+}\right)$ions, and selectively increase membrane permeability. The disruption of cation gradients/ transport caused by hydraphiles inhibits efflux pump activity, whereas increased membrane permeability allows for higher antibiotic influx. As a result the antibiotic concentration in the cytoplasm of MDR bacteria increases, and its activity is recovered. The amphiphile we call benzyl $\mathrm{C}_{14}$ hydraphile $\left(\mathrm{BC}_{14} \mathrm{H}, 4\right)$ is our most potent adjuvant: it rescues the antibiotic potency in resistant E. coli, MDR Klebsiella pneumoniae, and Staphylococcus aureus. E. coli failed to develop resistance to $\mathrm{BC}_{14} \mathrm{H}$ over 15 days. $\mathrm{BC}_{14} \mathrm{H}$ also shows generally lower mammalian cytotoxicity than does colistin.

\section{Experimental section}

\section{Compounds used}

Synthetic amphiphiles and antibiotics were used for the studies reported here. Synthetic amphiphiles used are called hydraphiles. Hydraphiles were synthesized in the Gokel lab and purity was confirmed by NMR and mass spectrometry. Four hydraphiles differing in its spacer chain lengths were used. We used benzyl $\mathrm{C}_{8}, \mathrm{C}_{10}, \mathrm{C}_{12}$ and $\mathrm{C}_{14}$ hydraphile. The antibiotics of choice were tetracycline, ampicillin, ciprofloxacin, and colistin. CCCP and reserpine, known efflux pump inhibitors were also used as controls. Gramicidin-D, valinomycin and Triton X-100 were used as ion transport and detergent controls. All the antibiotics, known EPIs and controls were received from SigmaAldrich and used as received. Hydraphiles, gramicidin-D, and valinomycin were dissolved in DMSO. All the other compounds were dissolved in autoclaved milli-Q $\mathrm{H}_{2} \mathrm{O}$.

\section{Hydraphile syntheses}

Compounds 1, 2, 3, and 4 are analogs that differ only in the lengths of the polymethylene units connecting the two distal macrocycles to the central ring. Detailed syntheses are reported in N. S. Curvey, S. E. Luderer, J. K. Walker, and G. W. Gokel, Improved Syntheses of Benzyl Hydraphile Synthetic CationConducting Channels, Synthesis, 2014, 46, 2771-2779.

\section{Bacteria used}

There were 27 strains of bacteria used for this study. Most of the strains listed in Tables 1 and $\mathrm{S} 1 \dagger$ were cultured in cation adjusted Mueller Hinton II (MHII) media. The $S$. pneumoniae was cultured in CA-MHB with $5 \%$ LHB media. tet ${ }^{\mathrm{R}} E$. coli was prepared by transforming the competent JM109 E. coli with pBR322 plasmid (Carolina Biological). The transformation was performed using heat-shock method as outlined by the manufacturer (Promega). The resulting $E$. coli cells were tetracycline and ampicillin resistant and designated tet ${ }^{\mathrm{R}} E$. coli. The tet ${ }^{\mathrm{R}} E$. coli expressed tetA efflux pump and $\beta$-lactamase enzyme. tet ${ }^{\mathrm{R}} E$. coli was always used in LB media with $100 \mu \mathrm{g} \mathrm{mL}^{-1}$ ampicillin. The Klebsiella pneumoniae (ATCC BAA 2146 ${ }^{\mathrm{TM}}$ ) strain was acquired from ATCC. It is a clinical relevant strain (BSL-2) that was reported to be isolated from a patient's urine sample. The $K$. pneumoniae is reported to be resistant to more than 30 different antibiotics including classes such as carbapenems, fluoroquinolones, cephalosporins, macrolides and tetracyclines. It expresses efflux pumps from three different classes: RND, ABC and MFS. TetA is the MFS type efflux pump expressed in the $K$. pneumoniae, which is used for the combination study. The $K$. pneumoniae strain was used in the MHII media. S. aureus 1199B13 was a gift Dr Glenn Kaatz, it was cultured in MHII media as well.

\section{Minimal inhibitory concentration (MIC)}

tet $^{\mathrm{R}}$ E. coli was grown in LB Miller media containing $100 \mu \mathrm{g}$ $\mathrm{mL}^{-1}$ ampicillin. $K$. pneumoniae was grown in the cation adjusted MHII media. The cells were grown overnight from one colony forming unit (CFU) in $2 \mathrm{~mL}$ media. On the day of the experiment, bacteria were knocked back to $\mathrm{OD}_{600}=0.100$ and incubated at $37{ }^{\circ} \mathrm{C}$ until the $\mathrm{OD}_{600}$ reached $0.500\left(4 \times 10^{8} \mathrm{CFU}\right.$ $\left.\mathrm{mL}^{-1}\right)$. The cell density was adjusted to $4 \times 10^{6} \mathrm{CFU} \mathrm{mL}{ }^{-1}$. The $20 \mu \mathrm{L}$ diluted cells were added to each well (final volume/well $=$ $200 \mu \mathrm{L}$ ) after the addition of antibiotics or synthetic amphiphiles. The final cell concentration per well was $4 \times 10^{5} \mathrm{CFU}$ $\mathrm{mL}^{-1}$.

In a 96-well plate, first the media was added followed by addition of the compounds. The final volume of each well was $200 \mu \mathrm{L}$. Compounds were either dissolved in DMSO or $\mathrm{dH}_{2} \mathrm{O}$. Compounds were always administered at a constant volume such that the final DMSO concentration in each well was $0.5 \%$ volume/volume ( $1 \mu \mathrm{L}$ of final $200 \mu \mathrm{L})$. For combination studies, after the addition of amphiphiles, antibiotics were added. The compounds or antibiotics that were dissolved in $\mathrm{dH}_{2} \mathrm{O}, 10 \mu \mathrm{L}$ per well was used. In the case of DMSO alone control, $1 \mu \mathrm{L}$ of DMSO was added to each well. For $\mathrm{dH}_{2} \mathrm{O}$ control, $10 \mu \mathrm{L}$ of $\mathrm{dH}_{2} \mathrm{O}$ was added to each well. No compound or solvent was added for cells alone and media alone control. Contents of the well were thoroughly mixed by pipetting up and down three times. After mixing, $20 \mu \mathrm{L}$ cells were added to each well. The plates were incubated at $37{ }^{\circ} \mathrm{C}$ for $18-20$ hours. Results were collected by determining the OD at $\lambda=600 \mathrm{~nm}$ using a plate reader (BioTek Cytation 3). Each compound was tested in triplicate per plate. Percent inhibition was calculated by comparing to the cell alone 
Table 1 MIC screening of hydraphiles and antibiotics

\begin{tabular}{|c|c|c|c|c|}
\hline Strain ID & Antibiotic used & $\begin{array}{l}\text { [Antibiotic] } \\
(\mu \mathrm{M})\end{array}$ & $\begin{array}{l}\text { [Comp. 2] } \\
(\mu \mathrm{M})\end{array}$ & $\begin{array}{l}\text { [Comp. 4] } \\
(\mu \mathrm{M})\end{array}$ \\
\hline S. aureus (control) & Vancomycin & 0.5 & 6 & 1.5 \\
\hline MRSA (USA 300) & Vancomycin & 1 & 6 & 1.5 \\
\hline MRSA (control) & Vancomycin & 1 & 6 & 1.5 \\
\hline E. faecalis (control) & Daptomycin & 2.5 & 6 & 1.5 \\
\hline S. pneumoniae (control) & Vancomycin & $<0.1$ & 6 & 6 \\
\hline S. pneumoniae (R:Pen) & Vancomycin & 0.2 & 6 & 3 \\
\hline S. pneumoniae (R:Levo) & Vancomycin & 0.2 & 6 & 6 \\
\hline K. pneumoniae (ESBL, SHV-12) & Meropenem & 0.65 & 51 & 24 \\
\hline K. pneumoniae (ESBL, FQR) & Meropenem & 0.65 & 26 & 12 \\
\hline K. pneumoniae (KPC-2) & Meropenem & 83 & 51 & 24 \\
\hline P. aeruginosa (FQR) & Meropenem & 2.6 & $>100$ & 94 \\
\hline P. aeruginosa (R:Mero) & Meropenem & $>166$ & 100 & 47 \\
\hline E. cloacae $(\mathrm{FQR})$ & Meropenem & 1.3 & 26 & 24 \\
\hline E. cloacae (R:Mero) & Meropenem & 42 & 26 & 12 \\
\hline E. aerogenes (R:Cep) & Meropenem & $<0.33$ & 26 & 12 \\
\hline E. coli $(\mathrm{WT})$ & Meropenem & $<0.33$ & 13 & 3 \\
\hline E. coli (Tol-) & Meropenem & $<0.33$ & 13 & 3 \\
\hline
\end{tabular}

control. Growth inhibited of $\geq 90 \%$ was considered as the MIC. The data was reproduced 2 more times on two separate plates.

\section{Checkerboard}

In a checkerboard experiment, each column of the plate had different concentration of the amphiphile increasing by serial dilution. Two amphiphiles were tested per plate. Each row of the checkerboard experiment had different concentrations of antibiotics increasing by serial dilutions. The concentrations of amphiphile and antibiotic tested were 1/2, 1/4, 1/8, 1/16 and $1 /$ 32 the MIC. E. coli and $K$. pneumoniae were tested using the checkerboard experiment. The MIC procedure used for the checkerboard experiment was the same as outlined above. Cells and compound alone controls were also used. The checkerboard experiment did not have a biological replicate but the data was reproduced three times before reporting. The data was represented as a heat map.

\section{Growth curve}

The growth curve experiment was performed using tet ${ }^{\mathrm{R}}$ E. coli. The compounds studied using growth curves were benzyl $\mathrm{C}_{14}$ hydraphile and tetracycline. Here, the $E$. coli was grown overnight from one CFU in LB Miller media containing $100 \mu \mathrm{g} \mathrm{mL}$ ampicillin. On the day of the experiment the cells were knocked back in LB Miller media containing $100 \mu \mathrm{g} \mathrm{mL} \mathrm{m}^{-1}$ ampicillin, to $\mathrm{OD}_{600}=0.550$ before use. In a sterile $250 \mathrm{~mL}$ flask, $50 \mathrm{~mL} \mathrm{LB}$ media was added, followed by benzyl $\mathrm{C}_{14}$ hydraphile and tetracycline. The concentrations of benzyl $\mathrm{C}_{14}$ hydraphile tested were 1 and $2 \mu \mathrm{M}$. The concentrations of tetracycline tested were 220 and $900 \mu \mathrm{M}$. In addition, a growth curve containing a combination of benzyl $\mathrm{C}_{14}$ hydraphile $(1 \mu \mathrm{M})$ and tetracycline $(220 \mu \mathrm{M})$ was also tested. Cells only and DMSO $(0.5 \% \mathrm{v} / \mathrm{v})$ alone controls were also performed. Compounds were mixed by swirling the flask. To each flask, knocked back cells were added so that the final cell concentration in each flask was approximately $4 \times 10^{5} \mathrm{CFU} \mathrm{mL}{ }^{-1}$. The flasks were incubated at $37^{\circ} \mathrm{C}$ and 200 RPM. A $2 \mathrm{~mL}$ sample was taken every 30 minutes (for next 24 hours) to determine the OD at $\lambda=600 \mathrm{~nm}$. A graph was plotted for OD $v s$. time to generate a growth curve. Average of three trials was used to determine the optical density. Standard deviation in the results was used to plot the error bars.

\section{Localization in bacterial cells}

tet $^{\mathrm{R}} E$. coli was grown overnight from one CFU in LB miller media containing $100 \mu \mathrm{g} \mathrm{mL}{ }^{-1}$ ampicillin. E. coli was knocked back and grown to OD $(600 \mathrm{~nm})=1.300$ before use. Cells were centrifuged at $6500 \mathrm{RM}(3000 \times g)$ for 5 minutes and resuspended in PBS. Dansyl labeled $\mathrm{C}_{14}$ dansyl hydraphile $\left(C_{\mathrm{f}}=2\right.$ $\mu \mathrm{M})$ was added to $1990 \mu \mathrm{L}$ of cells. For co-localization study,

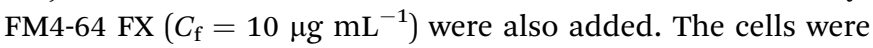
incubated for 5 minutes at $200 \mathrm{RPM}$ and $37{ }^{\circ} \mathrm{C}$. Cells were washed again at $6500 \mathrm{RPM}(3000 \times g)$ for 5 minutes and resuspend the cells in fresh PBS. A $20 \mu \mathrm{L}$ sample was loaded on to clean glass slide and covered with coverslip. The slide was observed using Zeiss LSM 700 microscope.

\section{E. coli membrane permeability using PI and FDA}

To test the membrane permeability of the tet $^{\mathrm{R}} E$. coli, the bacteria was first grown overnight from one CFU in media containing $100 \mu \mathrm{g} \mathrm{mL}{ }^{-1}$ ampicillin at $37^{\circ} \mathrm{C}$ and 200RPM. tet ${ }^{\mathrm{R}} E$. 
coli was then knocked back to OD $(600 \mathrm{~nm})=0.550$ before use. In a sterile test tube, cells were added followed by either Triton $\mathrm{X}-100$, DMSO or compounds 1-4 at half-MIC concentrations and incubated at $37{ }^{\circ} \mathrm{C}$ and 200 RPM. The concentration of DMSO was kept constant at $0.5 \%$ by volume in each case. After 30 minutes of incubation, the cells were washed by centrifugation at $3000 \times g$ for 5 minutes and re-suspended in sterile phosphate buffered saline (PBS). Propidium iodide $(30 \mu \mathrm{M}$, Thermo-Fischer) and fluorescein diacetate $(60 \mu \mathrm{M}$, SigmaAldrich) were added to the tet ${ }^{\mathrm{R}}$ E. coli cells in the PBS, mixed by vortexing and incubated at $37{ }^{\circ} \mathrm{C}$ and 200 RPM. After 30 minutes, the cells were washed again by centrifugation at 3000 $\times g$ for 5 minutes. The pellet was suspended in a fresh PBS, loaded onto a clean glass slide, covered with a cover slip and observed under Zeiss LSM 700 confocal microscope.

\section{Localization and permeability of HEK-293 cells}

HEK-293 cells were donated by Dr Michael Nichols. Cell lines were regularly maintained in growth media containing DMEM (ATCC), 10\% fetal bovine serum (FBS, ATCC) and 1\% penicillinstreptomycin solution (ATCC). Adherent HEK-293 cells were trypsinized using $0.25 \%(\mathrm{w} / \mathrm{v})$ trypsin-EDTA (Sigma-Aldrich), suspended in a fresh media and diluted to get a concentration of $3 \times 10^{5}$ cells per $\mathrm{mL}$. Cells were seeded in a 96-well plate $\left(100 \mu \mathrm{L}\right.$ per well) to get $3 \times 10^{4}$ cells per well. The plates were incubated for 24 hours at $5 \% \mathrm{CO}_{2}$ and $37{ }^{\circ} \mathrm{C}$ to reach a confluency of $80-90 \%$.

In a sterile $1.5 \mathrm{~mL}$ micro-centrifuge tube, dansyl $\mathrm{C}_{14}$ hydraphile and dansyl $\mathrm{C}_{16}$ lariat ether (0.5\% DMSO) were mixed with PBS. FM4-64 FX, DAPI and PI were also added to PBS for colocalization study. The spent media in the plate was replaced with $100 \mu \mathrm{L}$ media containing dansyl labeled amphiphiles and other stains. The cells were incubated at $37{ }^{\circ} \mathrm{C}$ and $5 \% \mathrm{CO}_{2}$ for 30 minutes before observing under Zeiss LSM 700.

For permeability study, the cells were cultured as outlined above. HEK-293 (90\% confluent) were then seeded in a 96-well plate to get 30000 cells per well. After 24 hours of incubation at $37{ }^{\circ} \mathrm{C}$ and $5 \% \mathrm{CO}_{2}$, the spent media was replaced with media (DMEM and $10 \%$ FBS) containing compound $1-4$ at $1 / 2 \times$ or $2 \times$ MIC. Triton X-100 at $0.1 \%$-by volume $(1670 \mu \mathrm{M})$ and DMSO $0.5 \%$ by volume were also used as controls. After 2 hours of incubation, spent media was replaced with PBS containing propidium iodide $(30 \mu \mathrm{M})$ and fluorescein diacetate $(60 \mu \mathrm{M})$ and incubated at $37{ }^{\circ} \mathrm{C}$ and $5 \% \mathrm{CO}_{2}$. After 2 hour of incubation, the spend media was replaced with fresh PBS and the cells were observed under Zeiss LSM 700 confocal microscope. The images were reported without any alterations. The gain and the intensity in all the images were kept constant.

\section{Scanning electron microscopy}

To perform scanning electron microscopy tet ${ }^{\mathrm{R}}$ E. coli was grown overnight from one CFU in LB miller media containing $100 \mu \mathrm{g}$ $\mathrm{mL}^{-1}$ ampicillin. E. coli was knocked back and grown to OD (600 $\mathrm{nm})=1.000$ before use. For $E$. coli alone control, the filter membrane $(0.45 \mu \mathrm{m})$ was dipped in the E. coli culture. E. coli was treated with various concentration of $\mathrm{C}_{8}$ and $\mathrm{C}_{14}$ hydraphiles for 10 minutes before loading on to filter membrane. The cells were fixed by transferring the filter membrane containing $E$. coli cells to $2.5 \%$ (v/v) glutaraldehyde (stock 25\%) for $60 \mathrm{~min}$. Cells were washed for 15 minutes by transferring the membrane in PBS. The cells were stained by transferring the membrane to $1 \%(\mathrm{v} / \mathrm{v}) \mathrm{OsO}_{4}$ for 1 hour. Serial dehydration of the sample was performed with $30 \%, 50 \%, 70 \%$, $80 \%, 90 \%, 100 \%, 100 \%(\mathrm{v} / \mathrm{v})$ ethanol. Sample was dipped in each ethanol concentration for 10 minutes. The cells were critical-point dried and sputter coated with gold before observing under JOEL 6320F SEM. The images were acquired and reports without any modifications.

\section{Potassium transport}

The experiment was conducted with tet ${ }^{\mathrm{R}}$ E. coli. E. coli was grown overnight from one CFU. Cells were knocked back to OD $=0.600$ before use. Cells were centrifuged at $2000 \times g$ and resuspended in sterile PBS. The OD of cells was adjusted to 1.300. To measure the $\mathrm{K}^{+}$leakage, $1998 \mu \mathrm{L} E$. coli suspended in PBS were added to a plastic cup containing magnetic stirrer. The stir plate was turned on to mix the sample and the potassium selective electrode (Orion, Thermo Scientific) was immersed in the sample so that just the membrane was covered in the sample. The voltage $(\mathrm{mV})$ was stabilized for 6-8 minutes. The temperature of the sample was kept constant at $25{ }^{\circ} \mathrm{C}$. The electrode was lifted and $2 \mu \mathrm{L}$ of the either of the hydraphiles or gramicidin-D were added. The DMSO concentration was kept constant at $0.1 \%(\mathrm{v} / \mathrm{v})$. The electrode was immersed back in the solution. Multiple concentrations were tested for each compound. The $\mathrm{mV}$ reading was recorded every 30 seconds for 15 minutes. The concentration of potassium ion released (mM) and $\Delta\left[\mathrm{K}^{+}\right] \mathrm{mM}$ were calculated using the equation from the calibration curve.

To determine the total potassium pool of tet ${ }^{\mathrm{R}} E$. coli, $2 \mathrm{~mL}$ of cells were heated at $100{ }^{\circ} \mathrm{C}$ for 30 minutes on a heat block. After 30 minutes the sample was cooled down to room temperature for 60 minutes. After 60 minutes the $\mathrm{mV}$ reading was recorded and $\Delta\left[\mathrm{K}^{+}\right] \mathrm{mM}$ was calculated. The experiment was performed in triplicates and standard deviation in the experiment was calculated.

\section{Efflux pump inhibition}

Efflux pump inhibition studies were conducted with $S$. aureus 1199B in a 96-well microtiter plate with black wells and glass bottom. S. aureus 1199B were grown overnight from one CFU. Cells were knocked back to $\mathrm{OD}_{600}=0.550$ before use. In a $1.5 \mathrm{~mL}$ micro-centrifuge tube, cell were spun down at $17000 \times$ $g$ for 3 minutes. Cell were re-suspended in fresh MHII media containing $10 \mu \mathrm{g} \mathrm{mL}^{-1}$ ethidium bromide and $100 \mu \mathrm{M} \mathrm{CCCP.}$ The $\mathrm{OD}_{600}$ was adjusted to 1.000 . The cells were vortexed and incubated at the room temperature for 20 minutes to load cells with ethidium bromide. After 20 minutes, the cells were centrifuged at $17000 \times g$ for 3 minutes. The supernatant was discarded and the cells were stored on ice. The tubes were warmed to room temperature for 5 minutes and MHII media was added to the tubes and $\mathrm{OD}_{600}$ was adjusted to $0.800 .100 \mu \mathrm{L}$ 
of ethidium bromide loaded cells were added to each well containing either $\mathrm{C}_{8}-\mathrm{C}_{14}$ hydraphiles, CCCP or reserpine. The contents were mixed by pipetting up and down once and the fluorescence was recorded immediately using Biotek Cytation 3 plate reader. Excitation of $530 \mathrm{~nm}$ and emission of $600 \mathrm{~nm}$ was used. Reading were collected every minute for 20 minutes. The results were reproduced two more times and standard deviation was calculated. The results were graphed against time.

\section{Ethidium bromide accumulation}

Efflux pump inhibition studies were conducted with $S$. aureus 1199B in a 96-well microtiter plate with black wells and glass bottom. S. aureus 1199B were grown overnight from one CFU. Cells were knocked back to $\mathrm{OD}_{600}=0.550$ before use. While the cells grew to the optimal conditions, hydraphiles, CCCP and reserpine stock concentrations were prepared. Mid-log phase cells were centrifuged at $17000 \times g$ for 3 minutes and resuspended in fresh MHII media. The $\mathrm{OD}_{600}$ was adjusted to 0.800 . In each well $200 \mu \mathrm{L}$ of cells were added followed by $10 \mu \mathrm{g}$ $\mathrm{mL}^{-1}$ of ethidium bromide and $1 \mu \mathrm{L}$ of $\mathrm{C}_{8}-\mathrm{C}_{14}$ hydraphiles, reserpine or CCCP. The contents of the well were mixed by pipetting up and down once. Immediately fluorescence was measured using the Biotek Cytation 3 plate reader. Excitation of $530 \mathrm{~nm}$ and emission of $600 \mathrm{~nm}$ was used. Reading were collected every minute for 20 minutes. The results were reproduced two more times and standard deviation was calculated. The results were graphed against time.

\section{Resistance development to hydraphiles}

The ability of tet ${ }^{\mathrm{R}} E$. coli to develop resistance to benzyl $\mathrm{C}_{14}$ hydraphiles and minocycline was determined using sequential culturing method. This method tests the ability of bacteria to develop resistance by inducing constant selective pressure of sub-lethal dose of antibiotics over 15 days. This procedure also accounts for only point mutations. The tet ${ }^{\mathrm{R}} E$. coli was grown overnight from one colony in LB media. E. coli was knocked back to OD $600 \mathrm{~nm}=0.100$ in a $2 \mathrm{~mL}$ LB media and grown to $\mathrm{OD}=0.550$. LB media was added to the test tubes, followed by the antibiotic and then the E. coli and incubated at $37{ }^{\circ} \mathrm{C}, 200$ RPM for 24 hours. Five different concentrations of hydraphiles and minocycline were set up: $0.25 \times, 0.5 \times, 1 \times, 2 \times$, and $4 \times$ MIC. Any cultures that grew at higher than the MIC levels were passaged on antibiotic-free LB Agar plates and the MIC is determined. The samples were also stored for future use. The cells were diluted from the second highest concentration that allowed growth at $1: 100$ in fresh media containing $0.25,0.5,1$, 2, 2.5 and 4 MIC. Test tubes were incubated at $37^{\circ} \mathrm{C}, 200 \mathrm{RPM}$ for 24 hours. Any cultures that grew at higher than the MIC levels were passaged on antibiotic-free LB Agar plates and the MIC was determined. The procedure was continued for 15 days. The results are represented in graphical format of MIC $v s$. days. Average from three trials was used to plot MIC on the graph.

\section{Mammalian cell cytotoxicity}

HeLa (ATCC CCL-2) cells were acquired from ATCC. Cos-7 (ATCC CRL-1651) cells were donated by Dr Cynthia Dupureur and HEK-293 cells were donated by Dr Michael Nichols. Cell lines were regularly maintained in growth media containing DMEM (ATCC), 10\% fetal bovine serum (FBS, ATCC) and 1\% penicillin-streptomycin solution (ATCC). Adherent HEK-293, HeLa and Cos-7 cells were trypsinized using $0.25 \%(w / v)$ trypsin-EDTA (Sigma-Aldrich), suspended in a fresh media and diluted to get a concentration of $3 \times 10^{5}$ cells per ml. Cells were seeded in a 96-well plate $\left(100 \mu \mathrm{L}\right.$ per well) to get $3 \times 10^{4}$ cells per well. The plates were incubated for 24 hours at $5 \% \mathrm{CO}_{2}$ and $37{ }^{\circ} \mathrm{C}$ to reach a confluency of $80-90 \%$.

In a sterile $1.5 \mathrm{~mL}$ micro-centrifuge tube, benzyl $\mathrm{C}_{8}-\mathrm{C}_{14}$ hydraphile, CCCP and colistin (0.5\% DMSO) were mixed with assay media (DMEM $+10 \% \mathrm{FBS}$ ) and serially diluted by 2 -fold each to get MIC, 1/2 MIC and 1/4 MIC concentrations. A control containing $0.5 \%$ DMSO was also prepared. After 24 hours, the spent media in the 96-well plate containing HEK-293, HeLa and Cos-7 cells (90\% confluency) was replaced with $100 \mu \mathrm{L}$ media containing the benzyl $\mathrm{C}_{8}-\mathrm{C}_{14}$ hydraphile, CCCP and colistin at various concentrations. The cells were incubated at $37{ }^{\circ} \mathrm{C}$ and $5 \% \mathrm{CO}_{2}$ for 24 hours before performing XTT assay (SigmaAldrich). The XTT assay was performed according to the manufacturer's protocol. After 24 hours of treatment with compounds, the media was replaced with PBS and $25 \mu \mathrm{L}$ XTT was added to each well. The XTT assay works by the reduction of tetrazolium compound by alive cells to the colored soluble formazan product. The absorbance of the product was measured at $450 \mathrm{~nm}$ (XTT) and $690 \mathrm{~nm}$ (background). Percent survival was calculated by comparing the average absorbance of cells treated with benzyl $\mathrm{C}_{8}-\mathrm{C}_{14}$ hydraphile, CCCP and colistin to that of cells alone. Three replicates were performed for each treatment. Average percent survival and standard deviation were calculated and plotted on a graph.

\section{Results and discussion}

\section{General}

Crown ethers ${ }^{14}$ form complexes with metallic and organic cations and transport them across various types of membranes. ${ }^{15}$ Hydraphiles were designed to use crown ethers as a module in a membrane-spanning scaffold to mimic protein channel functions. ${ }^{16}$ Examples of these synthetic, cationconducting amphiphiles are illustrated in Fig. 1. Hydraphiles typically possess three diaza-macrocycles connected by alkyl spacer chains and may be represented schematically as $\mathrm{R}\langle$ crown $\rangle \mathrm{C}_{n}\langle$ crown $\rangle \mathrm{C}_{n}\langle$ crown $\rangle \mathrm{R}$. Herein, the crowns are 4,13diaza-18-crown-6 $(\langle\mathrm{N} 18 \mathrm{~N}\rangle)$ and the connectors $\left(\mathrm{C}_{n}\right)$ are polymethylene chains ranging in length from hexylene $\left(\mathrm{C}_{6}\right)$ to

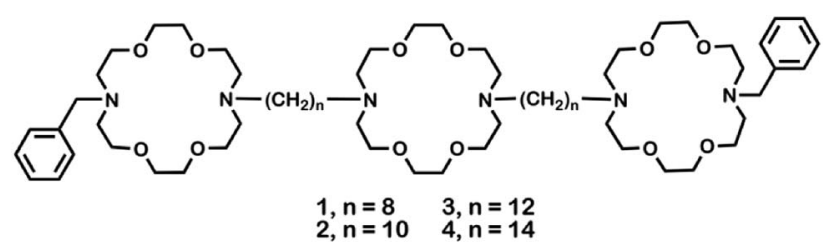

Fig. 1 Structures of hydraphiles studied. 
eicosylene $\left(\mathrm{C}_{20}\right) \cdot{ }^{17}$ The channels that most effectively conduct alkali metal cations ${ }^{14}$ have $\mathrm{C}_{n}$ chains of 12-16 methylenes. ${ }^{\mathbf{1 8 , 1 9}}$

These bilayer-spanning amphiphiles transport $\mathrm{Na}^{+}$ions through liposomes ${ }^{\mathbf{1 6}}$ and exhibit antibacterial properties. ${ }^{4} \mathrm{We}$ previously reported that $\mathrm{BC}_{14} \mathrm{H}$, when co-administered at sublethal concentrations, enhances the efficacy of erythromycin, kanamycin, rifampicin, and tetracycline against drug-sensitive E. coli, Pseudomonas aeruginosa, and Bacillus subtilis. ${ }^{\mathbf{2 0} 21}$ Based on the membrane activity of hydraphiles, we initially postulated that efficacy resulted only from a permeability enhancement mechanism. We now report evidence supporting the hypothesis that hydraphiles also inhibit efflux pump function by disrupting bacterial cation gradients.

Hydraphiles 1-4 have $N$-benzyl groups (R) on the distal macrocycles and linear $\mathrm{C}_{8}, \mathrm{C}_{10}, \mathrm{C}_{12}$, or $\mathrm{C}_{14}$ spacer chains (Fig. 1). ${ }^{22}$ Both ion transport and the antimicrobial activity of hydraphiles depend on the overall length of the hydraphiles. ${ }^{4}$ We expected benzyl $\mathrm{C}_{8}$ and $\mathrm{C}_{10}$ hydraphiles to be controls as they have shown poor ion transport through liposomes. ${ }^{14}$ The antibiotics studied were tetracycline (5), ciprofloxacin (6), and norfloxacin (7). The membrane disrupter colistin (8), the poreformer gramicidin-D (9), ${ }^{23}$ the carrier valinomycin (10), ${ }^{24}$ and the detergent Triton X-100 (11) ${ }^{25}$ served as controls. Known efflux pump inhibitors such as reserpine (12), ${ }^{21}$ and carbonyl cyanide 3-chlorophenylhydrazone (CCCP, 13) ${ }^{26}$ were also used as controls. Structures of controls and other hydraphiles are shown in Fig. S1.†

\section{Minimal inhibitory concentration studies}

We determined the MICs of benzyl $\mathrm{C}_{10}$ and benzyl $\mathrm{C}_{14}$ hydraphiles (compounds 2 and 4) as well as those for known antibiotic controls (vancomycin, daptomycin, and meropenem) against 24 bacterial strains. MICs were determined against sensitive and resistant strains of methicillin resistant $S$. aureus (MRSA), K. pneumoniae, E. coli, Enterococcus faecalis, Streptococcus pneumoniae, Acinetobacter baumannii, Pseudomonas aeruginosa, Enterobacter cloacae, and Enterobacter aerogenes (Table 1). Compound $\mathbf{4}$ was generally a more potent antimicrobial than 2. This activity correlates with the ability of $\mathrm{BC}_{14} \mathrm{H}$ (and not $\left.\mathrm{BC}_{10} \mathrm{H}\right)$ to span the membrane and to form ion-conducting pores.

It was observed that $\mathrm{BC}_{14} \mathrm{H}$ was more efficient than current treatment options against highly problematic VRE and MRSA (Gram-positive) strains. The MIC of daptomycin was $2.5 \mu \mathrm{M}$ against $E$. faecalis (VanA). The VanA and VanB clusters are responsible for vancomycin resistance in one in three hospital acquired enterococcal infections. ${ }^{1}$ The MIC for 4 against $E$. faecalis (VRE/VanA) and MRSA (USA 100, 300) was $1.5 \mu \mathrm{M}$. The MIC of vancomycin against MRSA was 1-2 $\mu \mathrm{M}$. Strains of vancomycin-resistant $S$. aureus have already been reported and USA 300 and USA 100 are the most common community-and hospital-associated strains. Based on the available treatment options and existing resistance development, $\mathrm{BC}_{14} \mathrm{H}$ could be considered for antimicrobial monotherapy against $E$. faecalis.

Synthetic amphiphiles typically show greater antimicrobial activity towards Gram-positive than Gram-negative bacteria. ${ }^{27}$
Even though the MICs of hydraphiles were higher (less potent) against Gram-negative than Gram-positive bacteria, hydraphiles were more active than controls against $A$. baumannii (FQR), $K$. pneumoniae (FQR), and E. cloacae (R:Mero). For example, $\mathrm{BC}_{14} \mathrm{H}$ was 28-fold, 3-fold and 2-fold more active, respectively, than meropenem against $A$. baumannii (FQR), K. pneumoniae (KPC2), and E. cloacae (meropenem resistant). The MIC of compound 4 ranged from 3-24 $\mu \mathrm{M}$ against these strains. The CDC has listed these bacteria as serious and urgent threats. ${ }^{1}$ Table 1 shows the results of screening for minimum inhibitory concentrations (MICs) against a variety of microbes.

\section{Adjuvant studies}

An urgent need lies with carbapenem resistant Enterobacteriaceae (CRE) and MRSA. It is known that combinations of antibiotics have a lower rate of resistance development than do individual antimicrobials. Our goal is to use hydraphiles as adjuvants to rescue the potency of antimicrobials against bacteria such as CRE and MRSA that are an urgent public health threat.

Typical approaches used to overcome resistance involve either inhibition of the $\beta$-lactamase enzyme or a combination of two (or more) different antibiotics. Even though efflux pumps are a major resistance mechanism, at present no efflux pump inhibitor is available for therapeutic use. Hydraphiles 1-4 were assessed for antimicrobial and adjuvant properties against efflux pump expressing MDR bacteria.

The bacteria used for these studies were $K$. pneumoniae and $E$. coli (Gram-negative), and $S$. aureus (Gram-positive). The $K$. pneumoniae (ATCC BAA 2146 ${ }^{\mathrm{TM}}$ ) strain was acquired from ATCC and reported to be isolated from a patient's urine sample. It expresses multiple different efflux pumps (e.g. RND, ABC, TetA). ${ }^{28}$ This strain is resistant to more than 25 different antibiotics and served in these studies as a clinically relevant control. The tetracycline resistant strain of E. coli $\left(\operatorname{tet}^{\mathrm{R}} E\right.$. coli) was developed by transforming $E$. coli with the pBR322 plasmid, which contains the tetA and AmpR genes. ${ }^{29}$ The tetA gene expresses the TetA efflux pump and AmpR gene expresses the $\beta$ lactamase enzyme. The TetA efflux pump depends on proton exchange for the transport of tetracycline. ${ }^{8}$ Since most of the virulent ESKAPE pathogens ${ }^{30}$ are Gram-negative, ${ }^{31}$ we assayed $E$. coli and K. pneumoniae. In addition, S. aureus 1199B overexpresses the NorA efflux pump and is resistant to both norfloxacin and ethidium bromide. ${ }^{13}$ This Gram-positive strain was tested with 1-4 to further evaluate NorA efflux pump inhibition. ${ }^{32}$

The MICs of compounds 1-4, tetracycline, ciprofloxacin, and norfloxacin were determined against tet $^{\mathrm{R}} \mathrm{E}$. coli, $K$. pneumoniae and $S$. aureus 1199B (Table S1 $\dagger$ ). Checkerboard experiments were then conducted with 1-4 to assess tetracycline potency against tet ${ }^{\mathrm{R}} E$. coli and $K$. pneumoniae and norfloxacin potency against $S$. aureus 1199B. The concentrations of 3 and $4((1 / 4)-$ (1/64) of MIC) used in the combination studies are recorded on the abscissas of graphs in Fig. 2. Combination studies with compounds 1 and 2 are shown in Fig. S2. $\dagger$ The ordinates record the concentrations of antibiotics used, also in fractions of MIC. 

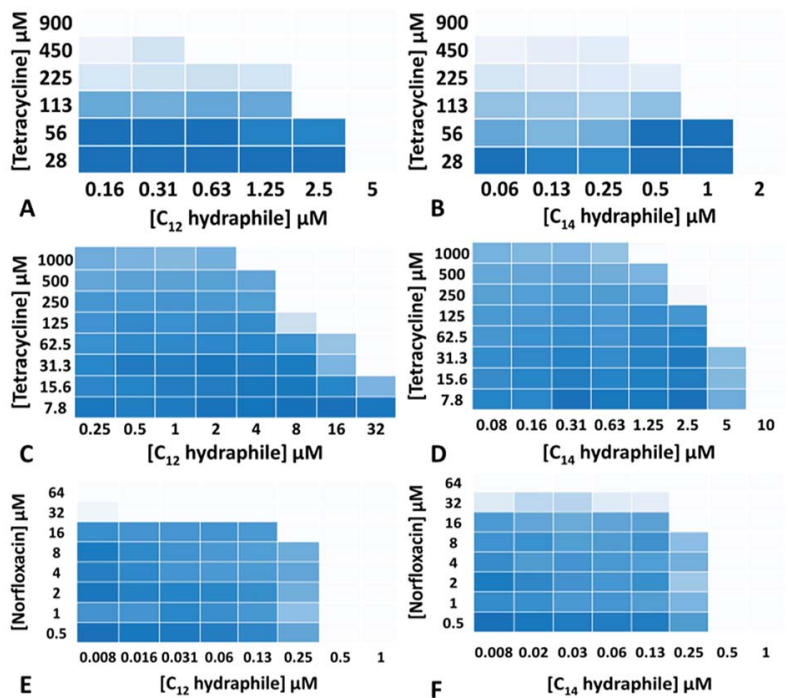

Fig. 2 Checkerboard experiments with compounds 3-4 with tetracycline against tet ${ }^{R} E$. coli $(A$ and $B$ ); with tetracycline against $K$. pneumoniae ( $C$ and $D$ ) and with norfloxacin against $S$. aureus $1199 \mathrm{~B}(\mathrm{E}$ and F). Color change from blue $(0 \%$ inhibition) to white ( $>90 \%$ inhibition) indicates increasing growth inhibition.

Bacterial growth in the presence of "hydraphile + antibiotic" combinations is indicated by a shade of blue. Uncolored boxes show that the potency (inhibition) of the combination was $\geq 90 \%$.

As seen in Fig. 2, even though the $\operatorname{tet}^{\mathrm{R}} E$. coli and $\mathrm{K}$. pneumoniae were resistant to tetracycline due to active efflux pumps, hydraphiles 3-4 successfully recovered tetracycline efficacy. The extent of tetracycline recovery depended on the concentration and the structure of hydraphile used. At $62 \mu \mathrm{M}$ (1/4 MIC) and $125 \mu \mathrm{M}(1 / 2 \mathrm{MIC})$ of $\mathrm{BC}_{8} \mathrm{H}(1)$, the MIC of tetracycline was decreased from $900 \pm 50 \mu \mathrm{M}$ to $82 \pm 15 \mu \mathrm{M}$ and $30 \pm 8 \mu \mathrm{M}$, respectively. This represents an increase in activity of tetracycline by 11 -fold and 30-fold, respectively. Similarly, at 1/2 MIC of benzyl $\mathrm{C}_{10}, \mathrm{C}_{12}$, and $\mathrm{C}_{14}$ hydraphiles, the activities of tetracycline in tet $^{\mathrm{R}} E$. coli were recovered by 23-, 16-, and 4-fold, respectively. The checkerboard experiments revealed that tetracycline activity was recovered at $8 \mu \mathrm{M}$ of $1,2 \mu \mathrm{M}$ of 2 , $625 \mathrm{nM}$ of 3 and $500 \mathrm{nM}$ of 4 against tet ${ }^{\mathrm{R}} E$. coli.

Most of the hydraphile-tetracycline combinations tested against tet ${ }^{\mathrm{R}} E$. coli had fractional inhibitory concentration (FIC) indices $^{33}$ of $\sim 0.5$. All of the hydraphiles showed some synergy with tetracycline as judged by the FIC $<1$ definition. Only $\mathrm{BC}_{8} \mathrm{H}$ at $1 / 4$ MIC (11-fold recovery) fits the narrower definition of synergy (FIC < 0.5). Growth curves (Fig. S3†) showed that 1-4 did not inhibit bacterial growth at $\leq 1 / 2$ MIC. We infer that when used in combination, inhibition occurs due to the increased efficacy of tetracycline rather than the additive effect of hydraphiles and tetracycline.

We queried whether hydraphile synergy would be observed with $K$. pneumoniae and $S$. aureus, and/or with antibiotics such as the fluoroquinolones. Against $K$. pneumoniae, which possesses multiple efflux pumps, the activity of tetracycline was recovered by $40-, 8-, 8-$, and 16 -fold at $1 / 2$ MIC each of 1-4, respectively (Fig. $2 \mathrm{c}$ and $\mathrm{d}, \mathrm{S} 2 \mathrm{c}$ and $\mathrm{d} \dagger$ ). Benzyl $\mathrm{C}_{8}-\mathrm{C}_{14}$ hydraphiles also recovered ciprofloxacin activity against $K$. pneumoniae (Table $\mathrm{S} 2 \dagger$ ). In this case, ciprofloxacin resistance results from both a point mutation and the presence of an efflux pump. Similar results were observed for ciprofloxacin against Grampositive bacteria. The greatest recovery of antibiotic activity was observed against $S$. aureus 1199B. At 1/2 MIC of compounds 1-4, the activity of norfloxacin was recovered by 128 -fold against NorA efflux pump expressing $S$. aureus 1199B (Fig. 2e and f, S2e and $f_{\dagger}^{\dagger}$ ). In the presence of $500 \mathrm{nM}$ of $\mathrm{BC}_{14} \mathrm{H}$ or $\mathrm{BC}_{12} \mathrm{H}$, the MIC of norfloxacin decreased from $64 \mu \mathrm{M}$ to $500 \mathrm{nM}$. We speculate that this greater potency enhancement is due to differences in the cytosolic membranes of Gram-negative and Gram-positive bacteria, the latter being more accessible to hydraphiles.

We next compared the activity of hydraphiles against $E$. coli to that of known ionophores. At $20 \mu \mathrm{M}$, a peptide ion channel (gramicidin-D), an ion carrier (valinomycin), and a detergent (Triton X-100) showed tetracycline efficacy enhancements of 1-, 2- and 2-fold, respectively, against tet ${ }^{\mathrm{R}}$ E. coli (Table S3 $\dagger$ ). Lower concentrations showed no recovery of tetracycline activity. No data were obtained for gramicidin-D or valinomycin, both of which were insoluble at $>20 \mu \mathrm{M}$.

Hydraphile activity was found to be similar to that of CCCP, an efflux pump inhibitor, and to colistin, a membrane disrupter. CCCP dissipates the proton gradient required for antibiotic efflux. ${ }^{25}$ At 1/2 MIC, CCCP and colistin recovered tetracycline activity by 4 -fold and 32 -fold, respectively (Table $\mathrm{S} 3 \dagger$ ). The FIC index for CCCP was 0.75 and for colistin it was 0.5. Toxicity limits the use of both CCCP and colistin as medicaments. ${ }^{34}$ Despite recent evidence of resistance, colistin is used as a treatment of last resort for MDR infections. We infer that in efflux pump expressing Gram-negative bacteria, membrane disruption also enhances antimicrobial activity. As such, the result of tetracycline recovery by $\mathrm{BC}_{8} \mathrm{H}$ is similar to that of colistin, albeit at a much higher concentration $(125 \mu \mathrm{M} v s .125$ $\mathrm{nM})$. The activity of efficient ion transporter $\mathrm{BC}_{14} \mathrm{H}$ is similar to that of CCCP, but hydraphiles may be functioning as membrane disrupters as well as indirect inhibitors of efflux pump activity.

Two conclusions can be drawn from the checkerboard data. First, the presence of hydraphiles 1-4 enhances antibiotic potency irrespective of drug or organism. Second, there is a general trend of higher potency correlated to amphiphile chain length. The efficacy of $\mathrm{Na}^{+}$ion transport by 1-4 through liposomal bilayers shows a similar trend. ${ }^{15}$ We infer that the hydraphiles insert in the bacterial membranes, likely enhancing permeability. Compounds 1-4, if of appropriate length, function as non-rectifying ion channels and alter the bacterial ion balance. This results in a deleterious effect on efflux pump function. Results confirming these hypotheses are discussed below.

\section{Membrane localization}

In order for hydraphiles to increase membrane permeability and to form cation selective channels, they must localize in the periphery/membrane of bacteria. Membrane localization of hydraphiles was assessed by using a $\mathrm{C}_{\mathbf{1 4}}$ hydraphile having two 
fluorescent dansyl groups attached to the distal macrocycles (Fig. S1 $\dagger$ ). ${ }^{4}$ The fluorescent dansyl-terminated $\mathrm{C}_{14}$ hydraphile was synthesized to use in tracking its localization in bacteria. Fig. 3 shows confocal images obtained in a study of $\operatorname{tet}^{\mathrm{R}}$ E. coli with dansyl $\mathrm{C}_{14}$ hydraphile $[4 \mu \mathrm{M}]$ and the fluorescent stain FM4-64 FX [5 $\left.\mu \mathrm{g} \mathrm{mL}^{-1}\right]$, used as a membrane-localizing control. The fluorescence intensity of the diphenylhexatrienyl dye FM4$64 \mathrm{FX}$ increases when it passes from aqueous media into the membrane. ${ }^{35}$

tet ${ }^{\mathrm{R}}$ E. coli cells were fixed with formaldehyde after a 5 minute treatment with FM4-64 FX followed by either a 30 second or 5 minute treatment with dansyl $\mathrm{C}_{14}$ hydraphile. Two data sets resulting from localization studies $(0.5$ and 5 minute treatments) are shown in Fig. 3. Bacteria were observed to be healthy as judged by the bright field image. The second column shows that FM4-64 FX localized in the bacterial membranes after both 30 seconds and 5 minutes. The FM4-64 FX staining was more visible after 5 minutes than after 30 seconds. Column 3 shows that dansyl $\mathrm{C}_{14}$ hydraphile (dansyl replaces benzyl in 4) localizes in the E. coli membrane within 30 seconds. As seen in the inserts in column 4 of Fig. 3 ( 30 seconds and 5 minutes), membrane localization of dansyl $\mathrm{C}_{14}$ hydraphile was confirmed in the overlay image of 'hydraphile (green) + FM4-64 FX (red)' that appears yellow in the membrane.

Three points were noted after treating $E$. coli with hydraphiles. First, membrane localization is apparent in the overlay image after only 5 minutes. Second, the cells showed cytoplasmic localization of dansyl $\mathrm{C}_{14}$ hydraphile (Fig. 3, bottom panel). This could result from either cell death or increased membrane permeability; both would permit hydraphile entry into the cytoplasm. Third, it appeared that hydraphile aggregates were present on or within the bacterial membrane. To confirm these observations, scanning electron microscopy (SEM) was conducted on hydraphile-treated E. coli. We also determined if hydraphiles formed aggregates before attaching to the bacterial surface by using SEM and dynamic light scattering (DLS). Images are shown in Fig. 4 and additional images are shown in Fig. S4. $\dagger$

As observed under SEM, the untreated E. coli showed a corrugated surface/membrane (Fig. 4(a)). As a control,

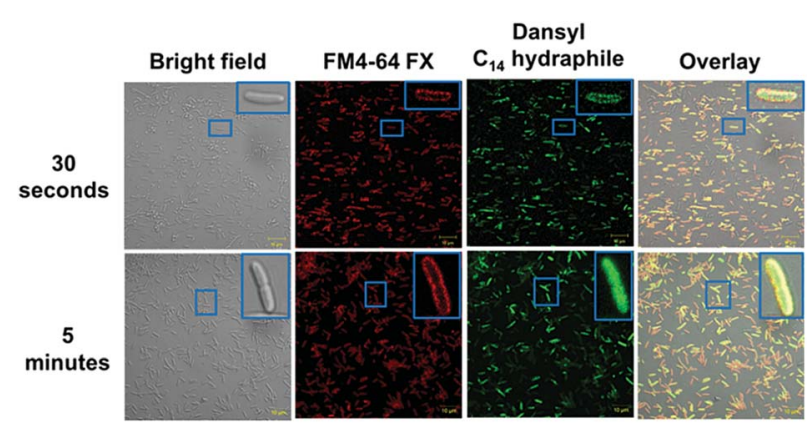

Fig. 3 Co-localization of FM4-64FX $\left(5 \mu \mathrm{g} \mathrm{mL} \mathrm{m}^{-1}\right)$ and dansyl $\mathrm{C}_{14}$ hydraphile in tet ${ }^{R} E$. coli. Top panel: FM4-64FX was fixed after 5 minutes and dansyl $\mathrm{C}_{14}$ hydraphile was fixed after 30 seconds. Bottom panel: FM4-64FX was fixed after 5 minutes and dansyl $C_{14}$ hydraphile was fixed after 5 minutes. The scale bars are $10 \mu \mathrm{m}$ (approximately the width of the smaller boxes).

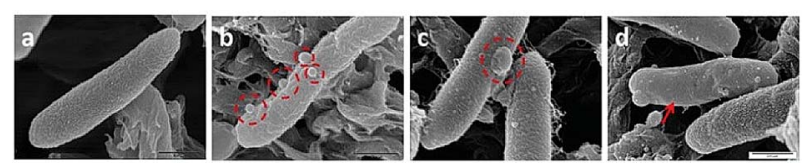

Fig. 4 Scanning electron microscopic images of common traits observed with tet ${ }^{R} E$. coli when treated with $\mathrm{BC}_{14} \mathrm{H}$ (4). The image shows the typical corrugated membrane of an untreated $E$. coli (a), hydraphile aggregates on $E$. coli surface (b), a membrane blister on the membrane (c), and membrane smoothening (d). The scale for all the images is $0.5 \mu \mathrm{m}$ (see panel d).

hydraphiles alone were observed under SEM. In aqueous media, SEM showed that benzyl $\mathrm{C}_{8}$ and $\mathrm{C}_{14}$ hydraphiles formed aggregates of $\sim 1-5.5 \mu \mathrm{m}$ (Fig. S5†). When studied using DLS, $\mathrm{BC}_{14} \mathrm{H}$ formed aggregates of $300 \pm 50 \mathrm{~nm}$ in $\mathrm{dH}_{2} \mathrm{O}$. The larger aggregates formed by hydraphiles under SEM conditions likely reflects differences in sample preparation. Notwithstanding, aggregates were observed in both cases.

Three observations were made by using SEM concerning $E$. coli treated with hydraphiles for 5 minutes. (1) Benzyl $\mathrm{C}_{8}$ and $\mathrm{C}_{14}$ hydraphile aggregates of size $226 \pm 9 \mathrm{~nm}$ and $164 \pm 22 \mathrm{~nm}$, respectively, were attached to the E. coli cell surface (Fig. 4(b)). The sizes of aggregates formed in LB Miller media using DLS were found to be $180 \mathrm{~nm}$ and $160 \mathrm{~nm}$ for $\mathrm{BC}_{14} \mathrm{H}$ at $7 \mu \mathrm{M}$ and 3.5 $\mu \mathrm{M}$, respectively. $\mathrm{BC}_{8} \mathrm{H}$ at $25 \mu \mathrm{M}$ in LB Miller media formed aggregates of $227 \mathrm{~nm}$ (DLS). (2) Membrane blisters and (3) smooth outer membranes were apparent in the hydraphiletreated E. coli cells (Fig. 4(c) and (d)). Disruption of cytoplasmic membranes is known to cause leakage of cytosolic contents into the periplasmic space, forming 'membrane blisters' on the surface of bacteria. ${ }^{36}$ This could account for the membrane blisters observed in the presence of hydraphiles. The outer membrane of $E$. coli is corrugated when the bacterium is in a well-balanced ionic condition. Disruption of the internal ion gradient may cause bacterial swelling, making the outer membranes smooth. ${ }^{4}$ Hydraphile-mediated deregulation of the cation gradient can cause osmotic stress leading to swelling and smoothening of the cellular membrane. The co-localization, DLS, and SEM studies confirm that the hydraphiles form aggregates that attach to the E. coli surface, followed by localization in $E$. coli membranes. The result is membrane disruption and osmotic stress.

The localization of dansyl $\mathrm{C}_{14}$ hydraphile was also assessed in human embryonic kidney (HEK-293) cells (Fig. S5 †), but only at $32 \mu \mathrm{M}$ in contrast with $4-8 \mu \mathrm{M}$ in E. coli. Some nuclear staining of HEK-293 cells with dansyl $\mathrm{C}_{14}$ hydraphile was also observed. Thus, hydraphiles localize in the membranes of both mammalian and bacterial cells, but in the former only when the hydraphile concentration is significantly higher. The concentration difference observed between $E$. coli and HEK-293 cells, while less than 10-fold, suggests that selectivity in treatment is possible.

\section{Membrane permeability}

The boundary membrane permeability of tet ${ }^{\mathrm{R}} E$. coli, S. aureus 1199B, and HEK-293 cell membranes were assessed by using 
propidium iodide (PI). PI is a membrane impermeable stain. If the permeability of the membrane increases, PI passes through the membranes, intercalates into the nucleic acid stack and its fluorescence intensity increases. Triton X-100 and colistin were used as controls. They both disrupt membranes, but Triton $\mathrm{X}$ 100 is a well-known detergent whereas colistin is an antibiotic. Compounds 1-4, and controls were tested at half their MICs.

The graph of Fig. 5(A) compares the efficacy of $\mathrm{BC}_{14} \mathrm{H}(4)$, at 1 $\mu \mathrm{M}, 2 \mu \mathrm{M}$, and $4 \mu \mathrm{M}$. At the concentration of bacteria required to conduct this experiment, the MIC of our most active compound (4) was $8 \mu \mathrm{M}$ against $E$. coli. Hence, 1/2 MIC of 4 for this experiment is $4 \mu \mathrm{M}$ against $E$. coli and it is $2 \mu \mathrm{M}$ against $S$. aureus. As shown in Fig. 5(A), Triton X-100 control at 0.1\% (1.6 $\mathrm{mM}$ ) increases membrane permeability in both $S$. aureus and $E$. coli. Colistin specifically targets Gram-negative bacteria; its potency (increase in permeability) against $E$. coli is $\geq 2 \mu \mathrm{M}$. As was the case with colistin, against $E$. coli, $\mathrm{BC}_{14} \mathrm{H}(4)$ increased membrane permeability only at $\geq 1 / 2 \mathrm{MIC}(4 \mu \mathrm{M})$. At $1 \mu \mathrm{M}$ or 2 $\mu \mathrm{M}$ of 4 , the membrane permeability of $S$. aureus was increased, but that of $E$. coli was either unaffected or showed only minimal changes. At 2 and $4 \mu \mathrm{M}$, compounds 1-3 showed no permeability increase for either $S$. aureus or $E$. coli (Fig. S6†). Thus, $\mathrm{BC}_{14} \mathrm{H}(4)$ was more active than hydraphiles 1-3 against $E$. coli and 4 was also more active against $S$. aureus than it was against E. coli.

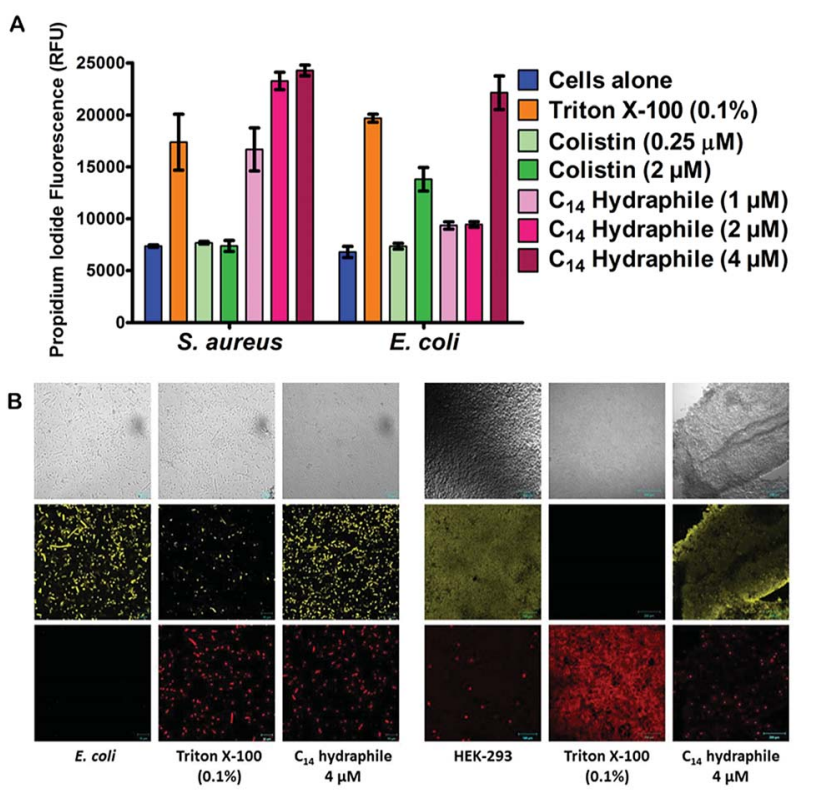

Fig. 5 (A) Permeability of propidium iodide to E. coli and S. aureus cell membranes mediated by compounds $1-4$, Triton X-100, and colistin. The $x$-axis represents the compounds used whereas the $y$-axis represents the relative fluorescence unit (RFU). Error bars represent standard deviation in three trials. (B) Benzyl $C_{8}-C_{14}$ hydraphiles (1/2 MIC) mediated permeability of propidium iodide and fluorescein diacetate in tet ${ }^{\mathrm{R}} \mathrm{E}$. coli $($ scale $=10 \mu \mathrm{m})$ and HEK-293 (scale $\left.=100 \mu \mathrm{m}\right)$. DMSO $(0.5 \% \mathrm{v} / \mathrm{v})$ and Triton $\mathrm{X}-100(0.1 \% \mathrm{v} / \mathrm{v})$ were used as controls. The top row shows bright field images, the middle row shows FDA fluorescence and the lower row shows propidium iodide (PI) fluorescence.
In the presence of $1 / 2 \mathrm{MIC}$ of compounds 1-4, the membrane permeability of $S$. aureus and $E$. coli were both increased (Fig. S6a and $\mathrm{b}_{\dagger}$ ). Likewise, at 1/2 MIC concentrations of hydraphiles, antimicrobial potency was increased, but bacterial growth was not inhibited in the absence of antibiotic. Evidence was obtained by using the cell viability stain fluorescein diacetate (FDA). FDA is non-fluorescent until hydrolyzed by endogenous esterases and thus reports cellular vitality. ${ }^{37}$ The fluorescence of propidium iodide (PI) and FDA in hydraphiletreated E. coli and HEK-293 cells was observed by confocal microscopy.

Fig. 5(B) shows tet ${ }^{\mathrm{R}}$ E. coli and HEK-293 cells after treatment with either $\mathrm{BC}_{14} \mathrm{H}$ or Triton $\mathrm{X}-100$. The images shown in the three left-hand columns of Fig. 5(B) show results for E. coli and the three columns on the right are for HEK-293. In the E. coli and HEK-293 cells treated with $\mathrm{BC}_{14} \mathrm{H}$, cellular viability (FDA panel) was comparable to that of the cells alone control. After treatment with compound 4, PI penetration (PI panel) clearly increased in $E$. coli, indicating enhanced membrane permeability. The increase in PI staining was comparable to that of Triton $\mathrm{X}-100$ at $0.1 \%$ (i.e. $1600 \mu \mathrm{M}$ ). Therefore, the increase in bacterial membrane permeability, as observed in Fig. 5(A) and (B), was not caused by cell death.

No increase in mammalian cell (HEK-293) membrane permeability was observed at either $1 / 2$ MIC or 2 MIC concentrations of compound 4 (Fig. 5(B)), which selectively increased the permeability of bacterial cells. Similar results were observed with $1 / 2$ MIC of benzyl $\mathrm{C}_{8}, \mathrm{C}_{10}$, and $\mathrm{C}_{12}$ hydraphiles (Fig. S7a $\dagger$ ). Compounds 1-3 increased the membrane permeability of $E$. coli cells without decreasing their cell viability and 1-3 did not increase mammalian cell permeability (Fig. S7b †). We speculate that membrane disruption and permeability increase occur at the site of hydraphile insertion.

Benzyl $\mathrm{C}_{8}-\mathrm{C}_{14}$ hydraphiles (1-4) localize in both bacterial and mammalian cell membranes, but are more disruptive of bacterial cell membranes and enhance their permeability to a greater extent. Some selectivity between bacterial and mammalian cells seems likely owing to differences in their structures. The phospholipids such as phosphatidylglycerols found in the bacterial membranes are acidic. ${ }^{38}$ The lipopolysaccharide of Gram-negative bacteria and teichoic acids of Gram-positive bacteria are anionic in nature. ${ }^{37}$ The cationic property and amphiphilic nature of antimicrobial peptides such as colistin, allow for interaction with bacterial membranes. ${ }^{39}$

Mammalian cells, on the other hand, have zwitterionic phosphatidylcholine in the outer leaflet and acidic phospholipids localized in the inner leaflet of membranes. ${ }^{40}$ Mammalian cell membranes also contain cholesterol. In previous liposomal studies with hydraphiles, addition of cholesterol to liposomes apparently thickened the membranes, shifting peak transport to longer chain lengths. The sensitivity of hydraphiles to membrane thickness suggests that some selectivity between mammalian and bacterial membranes is possible. ${ }^{\mathbf{1 6}}$ Hydraphile penetration of bacterial membranes suggests that (1-4) could increase membrane permeability and thus the influx of antibiotics into the cells. 


\section{Potassium transport}

Active efflux requires regulated cation gradients across bacterial membranes. Hydraphiles form cation selective channels in liposomal bilayers that transport sodium and potassium ions, but these channels are non-rectifying. Hydraphiles will transport ions from higher to lower concentrations without regulation. To assess hydraphile-mediated cation transport in bacteria, changes in extracellular potassium ion concentrations were measured after hydraphile addition to tet ${ }^{\mathrm{R}} E$. coli. Total potassium content of the tet ${ }^{\mathrm{R}} E$. coli cells, determined by boiling the bacteria at $100{ }^{\circ} \mathrm{C}$, was set to $100 \%$ and potassium cation release is reported on that basis. No change in extracellular $\left[\mathrm{K}^{+}\right]$ was observed with $0.1 \%(\mathrm{v} / \mathrm{v})$ DMSO control. The peptide ion channel gramicidin-D $[30 \mu \mathrm{M}]$ fostered $\mathrm{K}^{+}$efflux of $50-60 \%$ in tet $^{\mathrm{R}}$ E. coli (Fig. 6(A)). Compounds 1-4 were tested at $4 \mu \mathrm{M}$, which is $1 / 2$ the MIC of the most active hydraphile. In the presence of $4 \mu \mathrm{M}$ of benzyl $\mathrm{C}_{8}-\mathrm{C}_{14}$ hydraphiles, $6 \%$ (1), $4 \%$ (2), $21 \%$ (3), and $40 \%$ (4) of $\mathrm{K}^{+}$release was observed (Fig. 6(A)). The potassium release profile $\mathbf{4}>\mathbf{3}>\mathbf{2} \approx \mathbf{1}$ correlates directly with the potency enhancement of tetracycline against tet ${ }^{\mathrm{R}} E$. coli (Fig. S8a $\dagger$ ).

Loss of internal $\mathrm{K}^{+}$ion is known to occur when bacterial membrane integrity is compromised. We determined potassium release from $E$. coli as a function of increasing hydraphile concentration. As seen in Fig. 6(B), increase in the concentration of 4 , increases the potassium release from $E$. coli. The $\mathrm{K}^{+}$ release from $E$. coli also increased with increasing concentration of 1-3 (Fig. S8b-e †).

The gramicidin-D control showed $\mathrm{K}^{+}$release to the extent of 50-60\% (Fig. 6(A)) when administered at $30 \mu \mathrm{M}$. Potassium release by $\mathrm{BC}_{14} \mathrm{H}(4)$ at $4 \mu \mathrm{M}$ was $\sim 40 \%$. When the concentration of 4 was increased from $4 \mu \mathrm{M}$ to $6 \mu \mathrm{M}, 8 \mu \mathrm{M}$, and $10 \mu \mathrm{M}, \mathrm{K}^{+}$ ion release was enhanced (Fig. 6(B)). Indeed the gramicidin-D
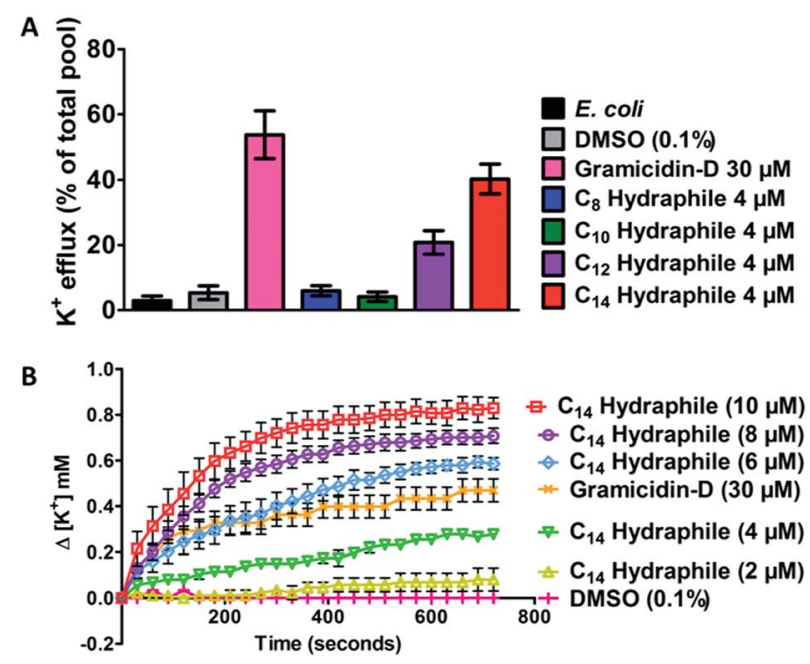

Fig. 6 (A) Potassium ion release from E. coli cells 10 minutes after treatment with DMSO, gramicidin-D (control) and benzyl $\mathrm{C}_{8}-\mathrm{C}_{14}$ hydraphiles (compounds 1-4). The total potassium pool of E. coli was determined by boiling the bacteria at $100{ }^{\circ} \mathrm{C}$ for 30 minutes. (B) Change in extracellular potassium concentration over 12 minutes of treatment with various concentrations of benzyl $C_{14}$ hydraphile (4). Error bars represent standard deviation in three trials. release level at $30 \mu \mathrm{M}$ was exceeded at $6 \mu \mathrm{M}$ of 4 . When the concentration of 4 reached $10 \mu \mathrm{M}$, more than $80 \%$ of the bacterial pool was released (Fig. 6(B)). No inhibition of E. coli growth was apparent at $1 / 2$ MIC of compound 4 . This indicates that at lower concentrations the cation release could be due to the ability of hydraphiles to form channels rather than as a result of membrane disruption or cell death. Membrane penetration and ion transport by hydraphiles is well established, but these two potential contributors have not yet been clearly distinguished. Both processes seem likely as is known for such peptide amphiphiles as colistin and daptomycin. ${ }^{\mathbf{4 1}}$ Among the compounds tested, the best ion transporters in liposomes ${ }^{15}$ also showed the highest level of $\mathrm{K}^{+}$release in $E$. coli-an interesting parallel considering how different are the boundary membranes.

\section{Efflux pump inhibition}

The combination of increased membrane permeability and disruption of cation gradients results in efflux pump inhibition. Efflux pump activity was assayed by evaluating changes in cytoplasmic concentrations of an efflux pump substrate. $S$. aureus (1199B) over-expresses the NorA efflux pump, for which ethidium bromide (EthBr) and norfloxacin are substrates. ${ }^{30}$ To the extent EthBr enters the cell cytoplasm, it intercalates with DNA, forming a complex in which fluorescence intensity is dramatically enhanced. Combination studies were first conducted to confirm that activity of either EthBr or norfloxacin could be recovered by compounds $\mathbf{1 - 4}$. The benzyl $\mathrm{C}_{8}-\mathrm{C}_{14}$ hydraphiles at 1/2 MIC increased the efficacy of EthBr against $S$. aureus by 2-, 26-, 8-, and 32-fold, respectively (Table S4†). Note that norfloxacin activity against $S$. aureus 1199B was also recovered by 1-4 as shown above in Fig. 2 .

Two studies were conducted to determine the effect of hydraphiles on bacteria expressing NorA efflux pumps. We first determined the ability of the bacterial NorA efflux pump to export EthBr in the presence or absence of hydraphiles (Fig. 7(A)). Thus, S. aureus 1199B cells were preloaded with EthBr by treating $S$. aureus 1199B with CCCP $[100 \mu \mathrm{M}]$, a known efflux pump inhibitor. Extracellular EthBr and CCCP were removed by washing the cells, followed by addition of $4 \mu \mathrm{M}$ of $\mathbf{1}$, 2,3 , or 4 . The MIC of $\mathrm{BC}_{14} \mathrm{H}(4)$ is $\sim 8 \mu \mathrm{M}$ against $S$. aureus (at $\left.\mathrm{OD}_{600} \sim 0.800\right)$, i.e. $[4 \mu \mathrm{M}]=1 / 2$ MIC. The graph of Fig. $7(\mathrm{~A})$ compares the effect on $S$. aureus 1199B of hydraphiles and known efflux pump inhibitors. EthBr's fluorescent intensity decreased similarly with untreated and $0.5 \%$ aq. DMSO-treated S. aureus (Fig. 7(A)). The EthBr fluorescence was little affected by the presence of $4 \mu \mathrm{M}$ benzyl $\mathrm{C}_{10}, \mathrm{C}_{12}$, or $\mathrm{C}_{14}$ hydraphile. Efflux pump function was found to be inhibited to a similar extent by $\mathrm{BC}_{14} \mathrm{H}(4)$ at $4 \mu \mathrm{M}, \mathrm{CCCP}$ at $100 \mu \mathrm{M}$, and reserpine at $41 \mu \mathrm{M}$. When the concentrations of CCCP and reserpine were decreased to $4 \mu \mathrm{M}$, to match that of $\mathrm{BC}_{14} \mathrm{H}$, inhibition of NorA activity was $\sim 30 \%$ lower than for 3 or 4 . Benzyl $\mathrm{C}_{8}$ hydraphile at $4 \mu \mathrm{M}$ showed minimal/no NorA efflux pump inhibition in $S$. aureus.

A complementary experiment was conducted by observing cytoplasmic EthBr accumulation in S. aureus 1199B in the 

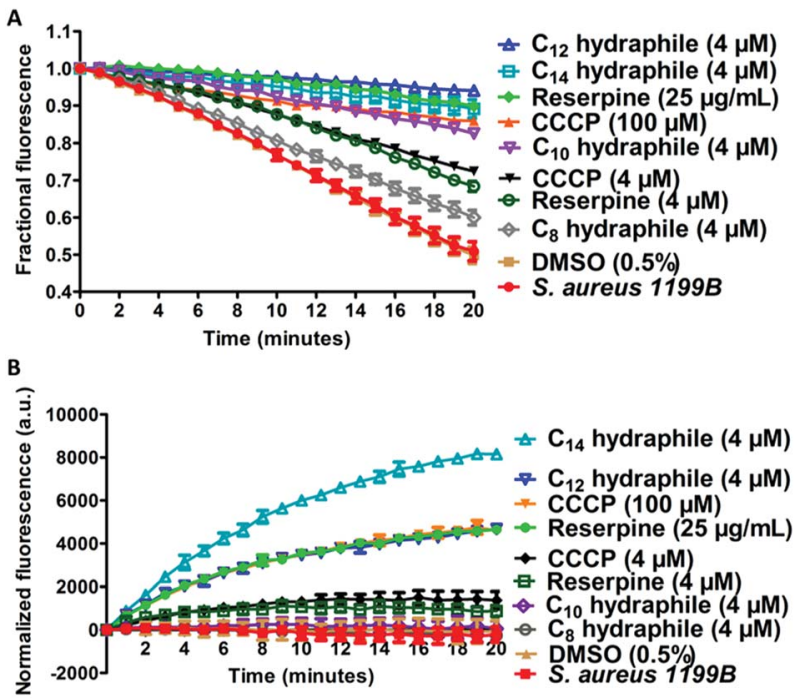

Fig. 7 Hydraphiles inhibit the activity of efflux pumps. (A) Release of ethidium bromide from $S$. aureus 1199B after treatment with reserpine, CCCP, benzyl $\mathrm{C}_{8}-\mathrm{C}_{14}$ hydraphiles [ $4 \mu \mathrm{M}$ ]. The abscissa reports time in minutes and the ordinate reports fractional fluorescence. (B) Accumulation of ethidium bromide in the presence of reserpine, CCCP, benzyl $C_{8}-C_{14}$ hydraphiles $(4 \mu M)$ in $S$. aureus 1199B. The abscissa records time in minutes and the ordinate records normalized fluorescence. The error bars represent the standard deviation in three independent trials.

presence of hydraphiles (Fig. 7(B)). EthBr was added to S. aureus 1199B cells followed by one of 1-4 or a control. Changes in fluorescence were monitored during $20 \mathrm{~min}$. The graph of Fig. 7(B) shows that EthBr accumulation was observed following addition of benzyl $\mathrm{C}_{12}$ and $\mathrm{C}_{14}$ hydraphiles, but not the $\mathrm{C}_{8}$ and $\mathrm{C}_{10}$ analogs. Note that the effect of $\mathrm{BC}_{12} \mathrm{H}$ at $4 \mu \mathrm{M}$ was similar to that of CCCP at $100 \mu \mathrm{M}$ and reserpine at $41 \mu \mathrm{M}\left(=25 \mu \mathrm{g} \mathrm{mL}{ }^{-1}\right)$. Benzyl $\mathrm{C}_{8}$ and $\mathrm{C}_{10}$ hydraphiles proved ineffective at $4 \mu \mathrm{M}$; higher concentrations of these compounds were not tested.

The data obtained with $S$. aureus 1199B show that hydraphiles inhibit efflux pump activity, causing antibiotics to accumulate in the bacterial cell cytoplasm. Benzyl $\mathrm{C}_{12}$ and $\mathrm{C}_{14}$ hydraphiles are at least comparable to and better, in some cases, than standard efflux pump inhibitors such as CCCP and reserpine. The hydraphiles could mediate both the accumulation of EthBr and inhibition of NorA efflux pump either by disruption of membrane integrity or uncoupling of the efflux pump from the ion gradient, or both.

The data obtained thus far confirm that hydraphiles localize in the membranes of both bacterial and mammalian cells. They affect the membrane permeability of bacterial cells, but they show little effect on mammalian cells. Their presence in bacterial membranes results in potassium efflux from the microbe's cytosol. Hydraphiles also inhibit efflux pump activity and allow for substrate accumulation in the bacterial cytoplasm. As a result, even at $\leq 1 / 2$ MIC of hydraphiles, the activity of antibiotics were recovered against MDR bacteria. Concerns over mammalian cytotoxicity and resistance development by $E$. coli to hydraphiles are obviously key questions and are addressed below.

\section{Cytotoxicity and resistance development}

The clinical use of both colistin and CCCP is limited due to cytotoxicity. ${ }^{42}$ Renal toxicity is a common issue with amphiphilic molecules..$^{34}$ For a hydraphile to be an effective antibiotic adjuvant, its cytotoxicity to mammalian cells should be low. The cytotoxicity was evaluated for benzyl $\mathrm{C}_{8}-\mathrm{C}_{14}$ hydraphiles against two mammalian epithelial cell lines: human embryonic kidney (HEK-293), and simian kidney (Cos-7). Colistin and CCCP served as controls. The viability of the cell lines in the presence of $1 / 2$ MIC of benzyl $\mathrm{C}_{8}-\mathrm{C}_{14}$ hydraphiles (1-4), colistin, and CCCP are recorded in Fig. 8(A) below.

CCCP was cytotoxic to all three cell lines. Colistin at $1 / 2$ MIC $(0.125 \mu \mathrm{M})$ was non-cytotoxic to Cos-7, but HEK-293 showed only about $60 \%$ survival. Similar to colistin, compounds 1-4 were completely non-cytotoxic ( $100 \%$ survival) to Cos-7 cell line at 1/2 MIC. Even at MIC concentrations of compounds 1-4, that are twice the concentrations required for adjuvant activity, the survival of Cos-7 was $100 \%$ (data not shown). The survival of HEK in the presence of $1 / 2$ MIC of $4(1 \mu \mathrm{M})$ was $70-80 \%$. Hence,
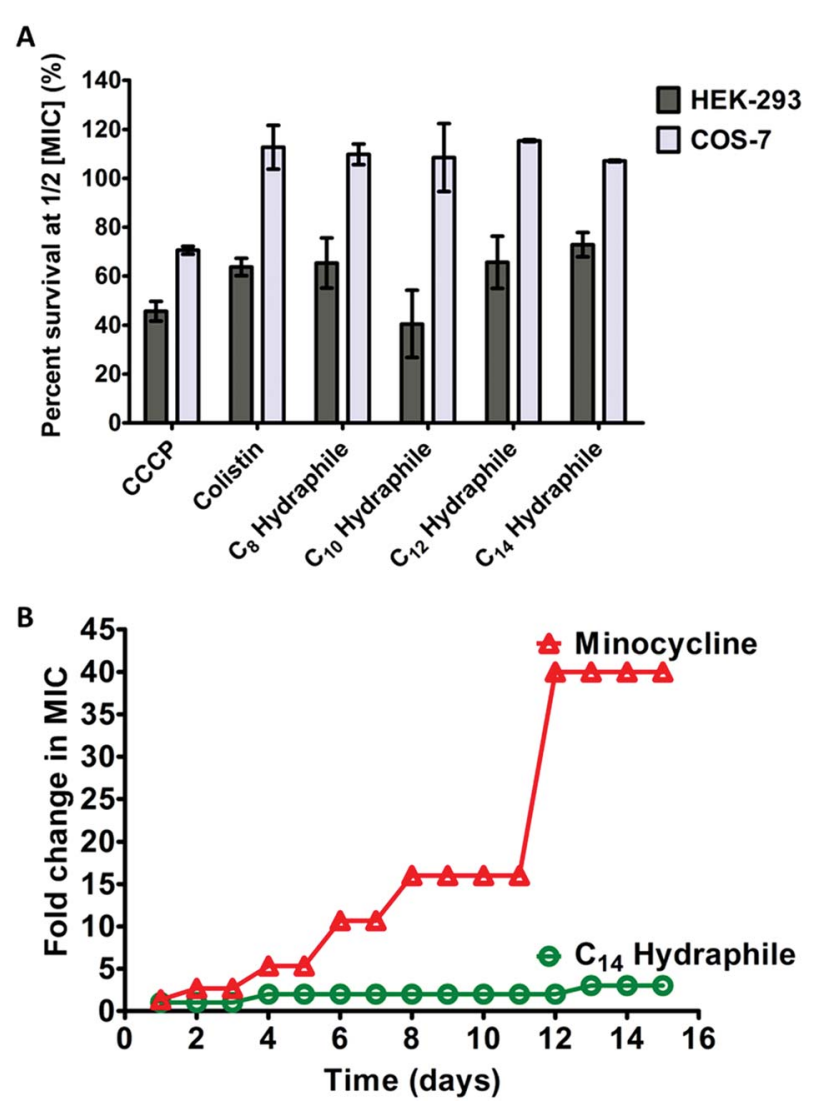

Fig. 8 Cytotoxicity and resistance development to benzyl hydraphiles. (A) Cytotoxicity of benzyl $\mathrm{C}_{8}-\mathrm{C}_{14}$ hydraphiles and colistin and CCCP at 1/2 MIC concentrations against HEK-293, and Cos-7 cells. The abscissa represents the compounds used and the ordinate represents the percent of cells that survived in the presence of the respective compounds. The error bars represent the standard deviation for three trials. (B) Resistance development by tet $^{R} E$. coli to $\mathrm{BC}_{14} \mathrm{H}$ (circles) and minocycline (triangles). The $x$-axis represents time in days and the $y$ axis represents increase in MIC (in folds). The data represents the average of three different trials. 
the cytotoxicity of $\mathrm{BC}_{14} \mathrm{H}(4)$ at $1 \mu \mathrm{M}$, is lower than that of colistin at $0.125 \mu \mathrm{M}$. The survival of HEK-293 cells in the presence of $1 / 2$ MIC of 1,2 , or 3 was $50-70 \%$, comparable to the cytotoxicity of colistin ( $60 \%)$.

We determined the median effective concentration $\left(\mathrm{EC}_{50}\right)$ of compound 4 against human hepatocytes (Fig. S9†). CCCP was used as a control. Survival of human hepatocytes was determined after treating them with $1-100 \mu \mathrm{M}$ of either compound 4 or CCCP for 72 hours. The $\mathrm{EC}_{50}$ for CCCP was found to be $5 \mu \mathrm{M}$. The $\mathrm{EC}_{50}$ for $\mathrm{BC}_{14} \mathrm{H}$ was $2.1 \mu \mathrm{M}$. At $1 \mu \mathrm{M}, 80-100 \%$ cell viability was observed for 4 . Thus, 4 , at concentrations of $500 \mathrm{nM}$ to 1 $\mu \mathrm{M}$, is non-cytotoxic to HEK-293, Cos-7, and human hepatocytes. At $1 \mu \mathrm{M} 4$ recovers antibiotic activity in MDR bacteria (Fig. 2), while being less cytotoxic than colistin. Analogs of 1-4 that show lower cytotoxicity might be required for clinical use. Additional analogs that show better solubility and lower cytotoxicity are under study.

A major concern with any antibiotic is bacterial resistance. Newer antibiotics are often limited in use to conserve their potency. Compounds that target membranes are usually less prone to resistance development by bacteria than those acting exclusively in the cytosol. For example, polymyxins (colistin) have been in clinical use for $>50$ years, but resistance to polymyxin was identified only recently. ${ }^{12}$ It is known that developing resistance to a membrane active compound would require multiple changes in membrane composition/synthesis pathways and is energetically unfavorable. ${ }^{2}$ The data reported here show that hydraphiles are membrane targeting molecules. We therefore exposed tet ${ }^{\mathrm{R}} E$. coli to $\mathbf{4}$ and to minocycline (positive control) by using the sequential culturing method. E. coli were treated with increasing fractional MIC concentrations of compound $\mathbf{4}$, for 15 days. The highest concentration of the compound that showed growth was used to determine MICs. Fig. 8(B) shows that tet ${ }^{\mathrm{R}}$ E. coli readily developed 40-fold resistance to minocycline (12-15 days). Resistance to 4 did not exceed 1.5- to 2 -fold during 15 days. Taken together, at its active concentration, $\mathbf{4}$ was less cytotoxic than colistin and not susceptible to resistance development in E. coli.

\section{Conclusions}

We present the results of a study showing the potential of synthetic ionophores-hydraphiles-as medicaments and as adjuvants. Hydraphiles and other synthetic ionophores have been known for decades. Most of the studies involving such molecules have focused on developing new structures, ${ }^{6}$ measuring their binding profiles, assessing their effect on ion transport, ${ }^{5}$ and simple surveys of antibacterial or antifungal properties. $^{26}$ This is the first report of a synthetic amphiphile that can be used to recover the efficacy of antibiotics against efflux pump expressing multidrug resistant bacteria or 'superbugs'. The hydraphiles recovered the activity of tetracycline and fluoroquinolones (ciprofloxacin, norfloxacin) against two Gramnegative and one Gram-positive bacteria. Ciprofloxacin and tetracycline activity were recovered by hydraphiles against MDR $K$. pneumoniae. This demonstrates that hydraphiles can be used to recover antimicrobial potency against MDR bacteria even when resistance arises from multiple resistance mechanisms. $\mathrm{BC}_{14} \mathrm{H}$ was most effective as an adjuvant against multiple different bacterial strains. Controls indicated that the activity of our synthetic ionophores is similar to that of the efflux pump inhibitor CCCP and to a membrane disrupting peptide such as colistin.

At sub-lethal concentrations, our synthetic ionophores resensitize resistant bacteria, likely by a combination of enhanced membrane permeability and by interrupting ion gradients required for efflux pump function. Studies revealed that hydraphiles form aggregates that attach to the bacterial surface followed by localizing in the cellular membrane. Hydraphiles then selectively increase membrane permeability in bacteria. Efflux pump activity was observed to be inhibited, presumably due to uncoupling of the cation gradient. As a result, more antibiotics pass through the membranes and accumulate in the cytosol. Such function recovers or increases the potency of existing antibiotics. We determined that among the compounds tested, $\mathrm{BC}_{14} \mathrm{H}$ was the most efficient amphiphile at recovering antimicrobial potency, increasing membrane permeability, cation transport and inhibiting efflux pump activity. $\mathrm{BC}_{14} \mathrm{H}$ showed greater activity against Grampositive bacteria, had the lowest mammalian cell cytotoxicity, and $E$. coli failed to develop resistance against it. Taken together, these novel synthetic amphiphiles hold forth potential as antibiotics per se and as adjuvants to enhance antimicrobial potency and to resensitize resistant pathogens.

\section{Conflicts of interest}

There are no conflicts to declare.

\section{Acknowledgements}

We thank the National Science Foundation (CHE-1307324, 1710549), the National Institutes of Health Preclinical Services Program, and the University of Missouri for partial support of this work. We are also grateful to Dr David Osborn for his assistance with microscopy.

\section{Notes and references}

1 (a) Center for Disease Control and Prevention, Antibiotic resistance threats in United States, 2013; (b) World Health Organization, Antimicrobial resistance global report and surveillance, 2014.

2 L. L. Ling, T. Schneider, A. J. Peoples, A. L. Spoering, I. Engels, B. P. Conlon, A. Mueller, T. F. Schäberle, D. E. Hughes, S. Epstein, M. Jones, L. Lazarides, V. A. Steadman, D. R. Cohen, C. R. Felix, K. A. Fetterman, W. P. Millett, A. G. Nitti, A. M. Zullo, C. Chen and K. Lewis, A new antibiotic kills pathogens without detectable resistance, Nature, 2015, 517, 455-459.

3 B. M. Hover, S. Kim, M. Katz, Z. Charlop-Powers, J. G. Owen, M. A. Ternei, J. Maniko, A. B. Estrela, H. Molina, S. Park, D. S. Perlin and S. F. Brady, Culture-independent discovery of the malacidins as calcium-dependent antibiotics with 
activity against multidrug-resistant Gram-positive pathogens, Nat. Microbiol., 2018, DOI: 10.1038/s41564-0180110-1.

4 W. M. Leevy, G. M. Donato, R. Ferdani, W. E. Goldman, P. H. Schlesinger and G. W. Gokel, Synthetic hydraphile channels of appropriate length kill Escherichia coli, J. Am. Chem. Soc., 2002, 124, 9022-9023.

5 B. G. Cox and H. Schneider, Coordination and Transport Properties of Macrocyclic Compounds in Solution, Elsevier, Amsterdam, 1992, p. 420.

6 J. W. Steed and J. L. Atwood, Supramolecular Chemistry, John Wiley and Sons, Ltd., Chichester, 2009.

7 K. Poole, Efflux mediated multiresistance in Gram-negative bacteria, Clin. Microbiol. Infect., 2004, 10, 12-26.

8 P. McNicholas, I. Chopra and D. M. Rothstein, Genetic analysis of the tetA(C) gene on plasmid pBR322, $J$. Bacteriol., 1992, 174, 7926-7933.

9 S. B. Levy, Active efflux mechanisms for antimicrobial resistance, Antimicrob. Agents Chemother., 1992, 36, 695-703.

10 H. I. Zgurskaya, C. A. Lopez and S. Gnanakaran, Permeability barrier of Gram-negative cell envelopes and approaches to bypass it, ACS Infect. Dis., 2015, DOI: 10.1021/ acsinfecdis.5b00097.

11 (a) B. Fan, J. Guan, X. Wang and Y. Cong, Activity of Colistin in combination with meropenem, tigecycline, fosfomycin, fusidic acid, rifampicin or sulbactam against extensively drug-resistant Acinetobacter baumannii in a murine thighinfection model, PLoS One, 2016, DOI: 10.1371/ journal.pone.0157757; (b) I. M. Gould, J. M. Miro and M. J. Rybak, Daptomycin: The role of high-dose and combination therapy for Gram-positive infections, Int. J. Antimicrob. Agents, 2013, 42, 202-210.

12 P. McGann, E. Snesrud, R. Maybank, B. Corey, A. C. Ong, R. Clifford, M. Hinkle, T. Whitman, E. Lesho and K. E. Schaecher, Escherichia coli harboring mcr-1 and blaCTX-M on a novel lncF plasmid: first report of mcr-1 in the United States, Antimicrob. Agents Chemother., 2016, 60, 4420-4421.

13 G. W. Kaatz, S. M. Seo and C. A. Ruble, Efflux mediated fluoroquinolone resistance in staphylococcus aureus, Antimicrob. Agents Chemother., 1993, 37, 1086-1094.

14 G. W. Gokel, Crown Ethers and Cryptands, The Royal Society of Chemistry, London, England, 1991, vol. 3, p. 190.

15 Y. Inoue and G. W. Gokel, Cation Binding by Macrocycles, Marcel Dekker, New York, 1990, p. 761.

16 G. W. Gokel, Hydraphiles: Design, Synthesis, and Analysis of a Family of Synthetic, Cation-Conducting Channels, Chem. Commun., 2000, 1-9.

17 M. E. Weber, P. H. Schlesinger and G. W. Gokel, Dynamic Assessment of Bilayer Thickness by Varying Phospholipid and Hydraphile Synthetic Channel Chain Lengths, J. Am. Chem. Soc., 2005, 126, 636-642.

18 G. Srinivas, C. Lopez and M. Klein, Membrane bound hydraphiles facilitates cation translocation, J. Phys. Chem. $B, 2004,108,4231-4235$.

19 A. A. Skelton, V. M. Khedkar and J. R. Fried, All-atom molecular dynamics simulations of an artificial sodium channel in a lipid bilayer: the effect of water solvation/ desolvation of the sodium ion, J. Biomol. Struct. Dyn., 2016, 34, 529-539.

20 J. Aktins, M. B. Patel, Z. Cusumano and G. W. Gokel, Enhancement of antimicrobial activity by synthetic ion channel synergy, Chem. Commun., 2010, 46, 8166-8167.

21 M. B. Patel, E. C. Garrad, A. Stavri, M. R. Gokel, S. Negin, J. W. Meisel, Z. Cusumano and G. W. Gokel, Hydraphiles enhance antimicrobial potency against Escherichia coli, Pseudomonas aeruginosa and Bacillus subtilis, Bioorg. Med. Chem., 2016, 24, 2864-2870.

22 N. S. Curvey, S. E. Luderer, J. K. Walker and G. W. Gokel, Improved Syntheses of Benzyl Hydraphile Synthetic Cationconducting Channels, Synthesis, 2014, 46, 2771-2779.

23 B. A. Wallace, Gramicidin and related ion channel-forming peptides, Novartis Foundation, John Wiley \& Sons, Ltd., Chichester, 1999, 225, p. 273.ss.

24 M. Pinkerton, L. K. Steinrauf and P. Dawkins, Molecular structure and some transport properties of valinomycin, Biochem. Biophys. Res. Commun., 1969, 35, 512-518.

25 (a) P. Schlieper and E. De Robertis, Triton X-100 as a channel-forming substance in artificial lipid bilayer membranes, Arch. Biochem. Biophys., 1977, 184, 204-208; (b) T. K. Rostovtseva, C. L. Bashford, A. A. Lev and C. A. Pasternak, Triton channels are sensitive to divalent cations and protons, J. Membr. Biol., 1994, 141, 83-90.

26 A. Ardebili, M. Talebi, L. Azimi and A. R. Lari, Effect of efflux pump inhibitor CCCP on the minimal inhibitory concentration of ciprofloxacin in Acinetobacter baumannii clinical isolates, Jundishapur J. Microbiol., 2014, 1, 86918696.

27 G. W. Gokel, S. Negin and R. Cantwell, Crown Ethers, Comprehensive Supramolecular Chemistry, ed. J. L. Atwood, G. W. Gokel and L. J. Barbour, Elsevier Publishing Company, 2nd edn, 2017, vol. 3, pp. 3-48.

28 T. Leski, G. J. Vora and C. R. Taitt, Multidrug resistance determinants from NDM-1-producing Klebsiella pneumoniae in the USA, Int. J. Antimicrob. Agents, 2012, 40, 282-284.

29 J. W. Meisel, M. B. Patel, E. G. Garrad, R. Stanton and G. W. Gokel, Reversal of tetracycline resistance in Escherichia coli by noncytotoxic bis(Tryptophan)s, J. Am. Chem. Soc., 2016, 138, 10571-10577.

30 H. W. Boucher, G. H. Talbot, J. S. Bradley, J. E. Edwards, D. Gilbert, L. B. Rice, M. Scheld, B. Spellberg and J. Bartlett, Bad bugs, no drugs: no ESKAPE! An update from the infectious disease society of America, Clin. Infect. Dis., 2009, 48, 1-12.

$31 \mathrm{H}$. Nikaido, Prevention of drug access to bacterial targets: permeability barrier and active efflux, Science, 1994, 264, 382-388.

32 A. A. Neyfakh, C. M. Borsch and G. W. Kaatz, Fluoroquinolone resistance protein NorA of Staphylococcus aureus is a multidrug efflux transporter, Antimicrob. Agents Chemother., 1993, 37, 128-129.

33 M. C. Berenbaum, What is synergy?, Pharmacol. Rev., 1989, 41, 93-141. 
34 A. Trifi, S. Abdellatif, F. Daly, K. Mahjoub, R. Nasri, M. Oueslati, R. Mannai, M. Bouzidi and S. B. Lakhal, Efficacy and toxicity of high-dose colistin in multi-drug resistant Gram-negative Bacilli infection: a comparative study of matched series, Chemotherapy, 2015, 16, 190-196.

35 W. M. Leevy, G. M. Donato, R. Ferdani, W. E. Goldman, P. H. Schlesinger and G. W. Gokel, Synthetic hydraphile channels of appropriate length kill Escherichia coli, J. Am. Chem. Soc., 2002, 124, 9022-9023.

36 M. Hartmann, M. Berditsch, J. Hawecker, F. Ardakani, D. Gerthsen and A. S. Ulrich, Damage of the bacterial cell envelope by antimicrobial peptides gramicidin S and PGLa as revealed by transmission and scanning electron microscopy, Antimicrob. Agents Chemother., 2010, 54, 31323142.

37 L. C. F. Stubberfield and P. J. A. Shaw, A comparison of tetrazolium reduction and FDA hydrolysis with other measures of microbial activity, J. Microbiol. Methods, 1990, 12, 151-162.
38 P. Komaratat and M. Kates, The lipid composition of a halotolerant species of Staphylococcus epidermidis, Biochim. Biophys. Acta, 1975, 398, 464-484.

39 K. Matsuzaki, Control of cell selectivity of antimicrobial peptides, Biochim. Biophys. Acta, 2009, 1788, 1687-1692.

40 A. J. Verkleij, R. F. A. Zwaal, B. Roelofsen, P. Comfurius, D. Kastelijn and L. L. M. V. Deener, The asymmetric distribution of phospholipids in the human red cell membrane. A combined study using phospholipases and freeze-etch electron microscopy, Biochim. Biophys. Acta, 1973, 323, 178-193.

41 M. E. Falagas and S. K. Kasiakou, Colistin: the revival of polymyxins for the management of multidrug-resistant gram-negative bacterial infections, Clin. Infect. Dis., 2005, 40, 1333-1341.

42 A. Trifi, S. Abdellatif, F. Daly, K. Mahjoub, R. Nasri, M. Oueslati, R. Mannai, M. Bouzidi and S. B. Lakhal, Efficacy and toxicity of high-dose colistin in multi-drug resistant Gram-negative Bacilli infection: a comparative study of matched series, Chemotherapy, 2015, 16, 190-196. 